\title{
Vocabulary Acquisition Through Flowcharts
}

\section{Aaron Chao \\ Baiko Gakuin University}

\section{Reference Data:}

Chao, A. (2019). Vocabulary acquisition through flowcharts. In P. Clements, A. Krause, \& P. Bennett (Eds.), Diversity and inclusion. Tokyo: JALT.

In light of recent research on student-centered learning, researchers have highlighted the need for strategies and tools to foster learner autonomy. Particularly within the area of vocabulary acquisition, the need for such strategies and tools is justified by the scope and depth of vocabulary that a learner needs in order to achieve a high proficiency level in a foreign language. This paper proposes the use of flowcharts as a metacognitive vocabulary learning strategy that helps promote vocabulary acquisition as well as foster learner autonomy. The justification for using such a strategy is discussed as well as practical suggestions for how it can be used in the classroom. 近年における学生主体の学習に関する研究を探ってみると、研究者たちは学習者オートノミーを促進する(学習)方略とツ 一ルの必要性を強調している。特に語彙習得の分野において、このような方略とツールの必要性は、学習者が外国語(学習)に おいて高い習熟度に到達するために必要となる語彙の範囲と深みという観点から、正当化されるものである。本論文は、語彙 る。この方略を使用する正当性、またこの方略をクラスルームでどう用いるかという実践的な提議について梌討する。

$\mathrm{n}$ his seminal work, Autonomy and Foreign Language Learning, Henri Holec (1981) Introduced the concept of learner autonomy, which he defined as the "ability to take charge of one's own learning" (p. 3). In line with this definition, one key implication of learner autonomy is that the learner assumes control over his or her own learning process. Equally important to this notion of assuming control, however, is the need for governance. In other words, once the onus for the learning process has shifted from the teacher to the learner, he or she must have the skills necessary to manage and direct the learning process. Holec's intentional use of the term "ability" in his definition suggests that such skills are "not inborn but must be acquired either by 'natural' means or (as most often happens) by formal learning, i.e., in a systematic, deliberate way" (p. 3).

Although the importance of learner autonomy extends to every area of language learning, one particular area that has received much attention in recent years is vocabulary acquisition (Webb \& Nation, 2017). This is due to the centrality of vocabulary acquisition in language learning. Languages are made up of words-many words-and the extent to which one is able to function in a particular language is greatly dependent on one's knowledge of and ability to use these words. As Singleton (1999) put it, "The major challenge of learning and using a language-whether as L1 or L2-lies not in the area of broad syntactic principles but in the "nitty-gritty' of the lexicon" (p. 4). This echoes Wilkin's (1972) statement that "while without grammar very little can be conveyed, without vocabulary nothing can be conveyed" (pp. 111-112). As such, proponents of student-centered learning have promoted vocabulary-learning strategies (VLSs). Among these strategies, metacognitive strategies in particular, which are methods that help learners to "think about how they think," have received much attention in recent years (Anderson, 2002, p. 1). However, there is a perceived gap in metacognitive tools that directly help learners become better learners at the metacognitive level. This paper proposes the idea of using flowcharts as a metacognitive VLS and tool to provide language learners with a basic but broad mental framework that can guide them through the vocabulary acquisition process.

It should be noted that, as of yet, no empirical study of the proposed flowchart's effectiveness has been conducted. Although this suggests the possibility and the need for such studies in the future, this paper mainly focuses on the rationale for the use of flowcharts in vocabulary learning and acquisition (VLA). In the rest of the paper, this will be done by providing (a) an overview of current understandings in VLA studies, (b) a detailed explanation of the flowchart itself and the organizing principles behind it, and (c) practical implications and suggestions for its use within a classroom setting. Four principles for VLA are also outlined to provide a grounding for the use of the flowchart. 


\section{Background}

\section{Scope of Vocabulary}

One of the central issues surrounding vocabulary acquisition is just how many words one has to know for sufficient coverage of written and spoken discourse. According to Nation (2006), 8,000 to 9,000 of the most frequent word families are needed in order to enable understanding of written discourse (e.g., newspapers and novels). Word families are defined by Bauer and Nation (1993) as consisting of "a base word and all its derived and inflected forms that can be understood by a learner without having to learn each form separately" (p. 253). For example, for the word go, the following words would be considered as part of the same word family: went, gone, and going. For academic spoken discourse, Dang and Webb (2014) found that the number of words needed to enable understanding is 4,000 word families (as cited in Nation, 2017).

\section{Knowing a Word}

The difficulty of achieving such a broad vocabulary size is compounded by the depth of knowledge that a learner must possess for even a single vocabulary item. Knowing a word extends far beyond simple word recognition. According to Moras (2001), it includes the following: meaning, form, part of speech, homonymy, homophony, pronunciation, polysemy, synonymy, collocations, style, and register (pp. 1-2). Nation (2013) broke down what knowing a word entails into the three large categories of form, meaning, and use, which are further broken down into subcategories. These various aspects of a word contribute much to what Nation (2013) referred to as the learning burden. Particularly for English language learners in contexts where differences in the grammatical and semantic features compared with their L1 are relatively large, this learning burden can be considerably cumbersome. These factors of vocabulary size and the learning burden make learner autonomy an important aspect of vocabulary acquisition.

\section{Vocabulary Learning Strategies}

In terms of VLSs, a number of taxonomies have emerged in recent years (Gu, 2013; Nation, 2001; Schmitt, 1997). Among these taxonomies, Schmitt's taxonomy is perhaps the most often used (see Figure 1).

\begin{tabular}{cc}
\hline Discovery & Consolidation \\
\hline Determination strategies & Social strategies \\
Social strategies & Memory strategies \\
& Cognitive strategies \\
& Metacognitive strategies \\
\hline
\end{tabular}

Figure 1. Schmitt's taxonomy of vocabulary learning strategies (1997).

According to Schmitt's taxonomy of VLSs, the various strategies can be broadly divided between discovery strategies-strategies that a learner uses when discovering the meaning of new words-and consolidation strategies-strategies that a learner uses to incorporate those words into their word repertoire. Among the two discovery strategies that Schmitt specified, the main difference lies in whether the meaning is discovered through social interaction with others (i.e., asking teachers/classmates and group work) or through nonsocial means (i.e., dictionary, flash cards, and word lists).

For consolidation strategies, Schmitt (1997) divided them further between social, memory, cognitive, and metacognitive strategies. Memory strategies involve using some type of semantic map, keyword, or word association methods to aid with retention. Cognitive strategies "entail manipulation or transformation of information about words to be learned" through methods such as written repetition and keeping vocabulary notebooks (p. 757). The last of the four consolidation strategies that Schmitt highlighted are metacognitive strategies, which he described as "a conscious overview of the learning process and making decisions about planning, monitoring, or evaluating the best ways to study" (p. 757). Although Figure 1 of Schmitt's taxonomy for VLSs might look at a glance as if metacognitive strategies are subject to consolidation strategies, they, in fact, overarch the entire learning process. In light of the importance of metacognitive strategies, I believe that flowcharts can be used as such a strategy to guide the learning process.

\section{Metacognitive Strategies}

Chamot (2009) defined metacognition as "the learner's understanding of his or her own knowledge and thinking processes and the learner's ability to regulate his or her own learning" (p. 54). 
Figure 2. Metacognition.

Figure 2 depicts this idea in the form of two concentric circles. The inner circle represents what the learner knows and how the learner thinks. The outer and much larger circle represents metacognition as a higher order thinking process that looks at, examines, and makes judgments about what is contained in the inner circle. It is important to note that metacognition extends beyond the learners' knowledge base and thinking process to the learners themselves; the metacognitively aware learner is one who also understands his or her learning styles, strengths, weaknesses, attitudes, and perceptions as a learner.

The importance of metacognitive strategies in language learning cannot be understated. According to O'Malley, Chamot, Stewner-Mazanares, Russo, and Kupper (1985), "Students without metacognitive approaches are essentially learners without direction or opportunity to review their progress, accomplishments, and future directions" (p. 561). As such, the explicit and formal teaching of metacognitive strategies is crucial both for fostering learner autonomy and the vocabulary acquisition process. For the above reasons, I propose the use of flowcharts as a strategy and tool for doing just that.

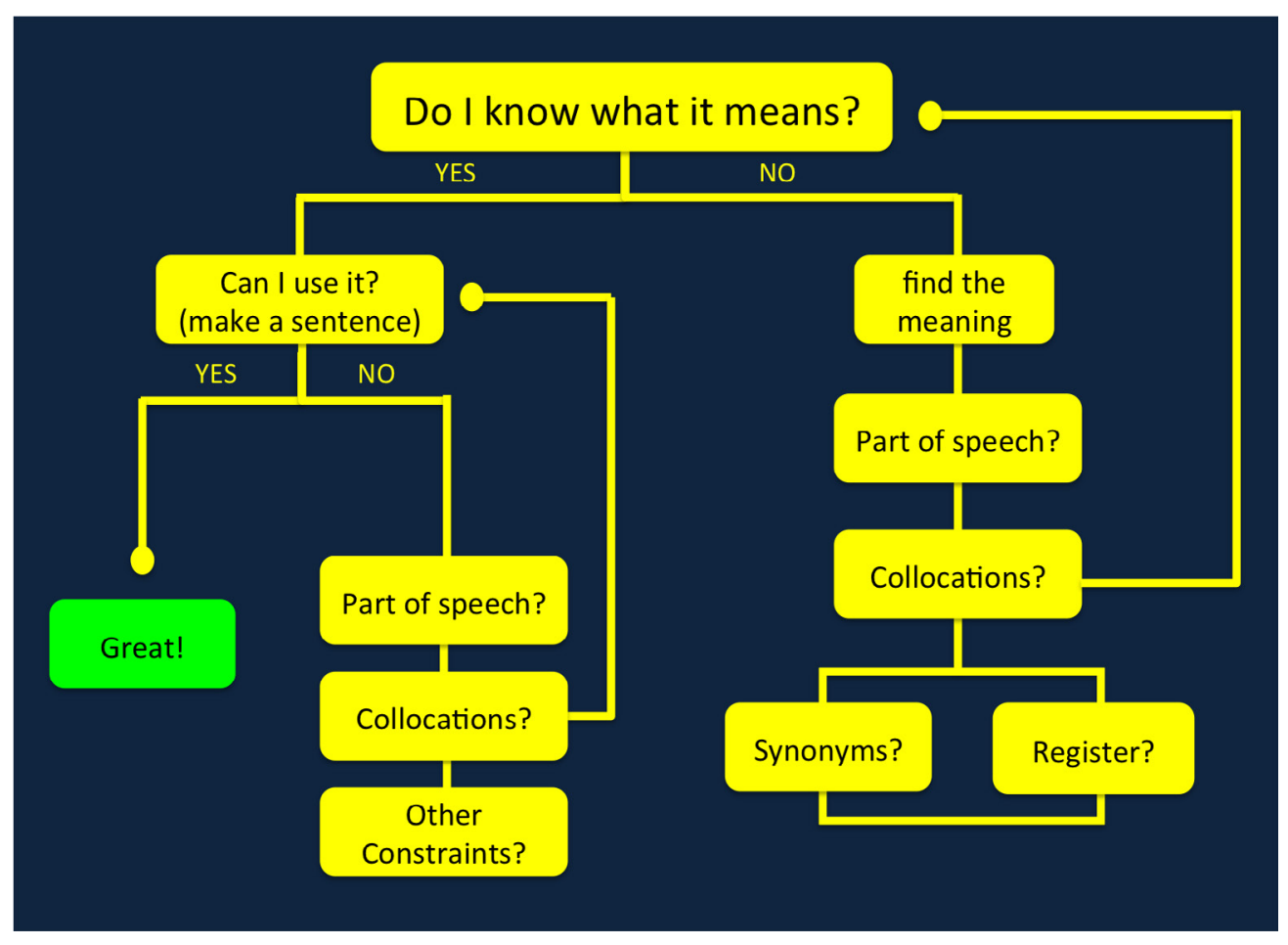

Figure 3. Proposed flowchart.

The flowchart in Figure 3 consists of guiding questions in abbreviated form. In full form, the chart consists of questions (see Figure 4).

\begin{tabular}{|ll|}
\hline Do I know what it means? & - What are its synonyms? \\
- What part of speech is it? & - What is the register? \\
$\begin{array}{ll}\text { Does it have any strong/weak } \\
\text { collocations? }\end{array}$ & - Are there any other constraints? \\
\hline
\end{tabular}

Figure 4. Flowchart questions. 
Organizationally, the chart can be broadly divided between the dimensions of knowledge (the right-hand side) and skill (the left-hand side). Knowledge deals with the different aspects of a word, but skill deals with putting that word to productive use. Although both sides include part of speech and collocations, the mindset of the learner switches from understanding to application.

As to synonyms and register, their placement beneath the line that extends back to top reflects the fact that they have been given less importance relative to part of speech and collocations. Especially for low-level learners, these aspects of learning vocabulary may not be relevant; therefore, they are to be considered according to the learner's discretion.

The learner is encouraged to evaluate any other constraints that might be preventing him or her from being able to productively use a word and make a sentence. This could simply be a realization that there is an insufficient understanding of a word, thus requiring the learner to go back to the right side of the flowchart. It could also include other constraints that are not explicitly depicted in the flowchart.

It should be noted that this flowchart is not all inclusive. There are other word aspects such as pronunciation, spelling, homonyms, and etymology that have been intentionally omitted from this flowchart. The rationale for not including such aspects is that doing so would go beyond the intended use of this flowchart, which is to provide students with a basic mental framework for vocabulary acquisition.

\section{Advantages of Using a Flowchart}

Visual

As a visual representation, a flowchart allows for the communication of a great deal of information; as the saying goes, "A picture is worth a thousand words." Therefore flowcharts can be used to better convey information about a complex process than if the process were described in text form. The proposed flowchart is a tool that can help the learner develop an awareness of the aspects of a word that need to be learned. It also helps the learner to develop a stronger awareness of the knowledge and skill dimensions of a word. Rather than simply focusing on the meaning and form of a word, the learner is encouraged to put it into use and to consider what the problems are if he or she is unable to do so.

Not only is a flowchart a visual representation, it is also a visual representation of a process. As such, there is a clear starting point as well as an end point. In between those points, there is a defined step-by-step sequence that shows how the different stages are interconnected. This helps the learner develop a broader overview of the vocabulary learning process. Internalizing such a framework can make the process seem more manageable, less intimidating, and less enigmatic.

\section{Troubleshooting}

Flowcharts are not only used for understanding processes; they can also be used to build in troubleshooting mechanisms. With regard to the proposed flowchart, if a learner feel that he or she understands a word but is not able to use it, the flowchart redirects his or her attention to part of speech and collocations, which are two aspects of words that are particularly important in the fostering of productive skills.

\section{Mental Framework}

Another advantage of flowcharts is that they can serve as a mental framework. Therefore, the learner is encouraged to internalize the questions and therefore internalize the vocabulary learning process. The hope is that, after some time, the learners will have not just memorized the questions, but also felt the weight of the importance of the different word aspects to the degree that they would intuitively monitor their thinking process with the most appropriate guiding question for any particular moment. This flowchart is meant to serve as a starting point for helping dynamic learners learn autonomously in accordance with their dynamic needs.

Also, adopting such a mental framework would hopefully encourage the learner to process and sift through the learning burden mentally. Much in the same way that mental math involves solving math problems in one's head without having to rely on visual aids or material resources, speaking often requires one to bring what is often a large amount of knowledge to bear in a moment's notice in order for successful communication to take place. Processing the information mentally, especially while making sentences and rehearsing them, would exercise the learner's ability to do just that.

\section{Principles of Vocabulary Acquisition}

It is important to have a set of principles to ground the use of any VLS or tool to ensure that it is being used properly and effectively. Following are four principles of vocabulary acquisition that I believe are of particular importance. 


\section{Select Carefully}

An important aspect of vocabulary acquisition is what words should be learned. For many language courses, the selection of words is determined by what words are included in the course textbook and/or syllabus. In some cases, the learners may have more freedom to choose what they want to learn. Regardless of how the list of words to be learned is generated, there should be a level of awareness among both the teacher and the learners that "different words have different values" (Nation, 2013, p. 6).

In terms of frequency, some words are much more commonly used than others. Some words play more of a functional role (e.g., to for purpose), and other words are considered content words (e.g., car, beautiful). Some words are concrete (e.g., book, computer), and others are more abstract (e.g., creativity, desire). An awareness of lexical differences can help the learner be more strategic in word selection.

\section{Be Deliberate}

Although current research reflects differing opinions regarding whether vocabulary acquisition should be deliberate or incidental, it is hard to argue against the idea that deliberate vocabulary learning is needed at some level.

However, the nature of the proposed flowchart is not a fixed strategy for learners to use in isolation; rather, it is a metacognitive tool that is aimed at helping learners in the realm of higher thinking, so that they can plan, monitor, and evaluate the learning process as well as develop a stronger awareness of what it means to know a word. Therefore, regardless of whether the learning is taking place deliberately or incidentally, the flowchart can aid the learner in directing the learning process.

\section{Rehearse, Rehearse, and Rehearse}

Maintenance Rehearsal

This involves repeating a word in order to memorize it. Simply put, it is rote memorization. An example of this would be repeating a phone number to yourself until you are able to remember it. This can be applied to memorizing single lexical items, phrases, full sentences, and longer chunks. The flowchart encourages the learner to make a sentence once the meaning of a word is grasped. Afterwards, the learner should apply this maintenance rehearsal strategy at both the word and sentence level.

\section{Elaborative Rehearsal}

This involves thinking about a word deeply and wrestling with it from different perspectives. According to Smith (2000), "The more one manipulates, thinks about, and uses mental information, the more likely it is that one will retain that information" (p. 121). Effort should be made to link the target word with other words that are already a part of the learner's vocabulary; words learned in isolation are harder to remember. On the other hand, a deeper level of semantic mapping and processing can help lead to longterm retention (Baddeley, 1997).

\section{Expanding Rehearsal}

According to Baddeley (1997), expanding rehearsal "advocates that a given item should be initially tested after a very brief delay. If the subject correctly recalls it, then the delay should be systematically increased whereas if he or she is wrong the delay should be shortened" (p. 113). Alternative names for this memory strategy include spaced rehearsal and spaced repetition. Because the flowchart itself does not indicate so, the learner needs to take it upon him- or herself to regularly revisit words at varying intervals depending on their ability to recall and use a particular word.

\section{Be Aware of Personal Learning Styles/Strategies}

Learning styles refer to how a learner habitually responds to a learning environment cognitively, perceptually, and physiologically. With regard to school children in the U.S.A., Dunn (1983) found that learners preferred one of four main perceptual learning styles: visual (learning by seeing), auditory (learning by hearing), tactile (learning by feeling), or kinesthetic (learning by moving). Cognitively, learners have different habits for how they think and process things. Because the learning process is dynamic, learners should monitor and evaluate these habits to decide which VLSs should be implemented and how they should be implemented at any given moment. The flowchart being a visual tool, this may suggest that it would favour the visual learner. Even if that were the case, I believe that using a flowchart can benefit all types of learners even for the sake of serving as a point of reference for the various word aspects.

\section{Using the Flowchart in the Classroom}

For teachers who are interested in implementing the use of flowcharts in their classroom, a 5-phase procedure is recommended (see Figure 5). 


\begin{tabular}{ll}
\hline Phase & \multicolumn{1}{c}{ Content } \\
\hline 1 & Teacher gives brief overview of flowchart. \\
& Teacher explains four principles of vocabulary acquisition. \\
2 & The different aspects of English are explicitly taught. \\
3 & Students practice using the flowchart as a class under the teacher's guidance. \\
4 & Students use the flowchart independently. \\
& Teacher monitors student progress. \\
5 & Teacher evaluates student progress.
\end{tabular}

Figure 5. Five-phase procedure for implementing flowcharts.

Also, because the time frame for teaching the flowchart and helping students utilize it may differ greatly depending on proficiency level and other factors (e.g., age, size of class, cultural context), specific time frames are not given for each of the five phases.

\section{The Preparation Phase}

In this phase, a brief overview of the flowchart is given and the four principles for vocabulary acquisition are explained.

\section{The Teaching Phase}

During this phase, the different aspects of English contained in the flowchart are explicitly taught to the students. Depending on the level of the students, this may require a significant amount of time. This entails that teachers may need to spend a sufficient amount of time in teaching the students how to use the flowchart.

\section{The Practice Phase}

During this phase, students practice using the flowchart as a class. Teachers can choose a word and have all of the students learn the same word. The teacher guides the students through the flowchart and verbally asks the questions to reinforce the thinking process. It may also be beneficial at this stage to have students pair up or work in larger groups of three or four so that students can complement and help each other to think through the learning process. Teachers can also have students select their own word of choice during this phase.

\section{The Monitoring Phase}

During this phase, the students are tasked with using the flowchart independently. For example, teachers can task the students with learning 20 new words using the flowchart over a period of 1 week. Students are instructed to keep a notebook to record the gathered information as well as the sentence that they created. At the end of the 1-week period, students present their notebooks to the teacher to ensure that students have a correct understanding of the words and that the sentences have been constructed properly.

\section{The Evaluation Phase}

During this phase, the teacher evaluates the students on the assigned words to check for performance using an assessment method of their choice.

\section{Some Considerations \\ Making Sentences}

The learner should confirm that the sentences have been properly constructed and that the target vocabulary has been used correctly. This means that even after the five phases have been completed, continued monitoring and support are needed.

Regarding making sentences, a general rule of thumb is that the learner should try to create sentences that are strongly associated to what they know or what they have personally experienced. Creating such sentences will help with memory retention. Another rule of thumb is that, although the learner should try to make sentences that are meaningful to them, complex sentences that could potentially distract the learner from focusing mainly on the target word should be avoided. For this reason, the learner should also avoid adding additional unfamiliar words in the sentence-the only new word should be the target word.

\section{The Need for Adaptation}

Another point of discussion is the need for the flowchart to be adapted to one's needs. Depending on the language pair, the level of the students, and the culture/context in which the learning is taking place, the flowchart may need to be modified.

For a learner of Spanish whose native tongue is English, gender is an aspect that could be added to the flowchart because certain words in Spanish have a masculine form and others have a feminine form. For the Japanese learner of English, the part of speech stage 
of the flowchart might be branched further to include count and noncount nouns because Japanese nouns do not have a singular or plural form as English nouns do.

For lower level learners, finding synonyms or cognates and thinking about the style or register of the word may be of less importance. Conversely, the parts of speech section might be extended to spell out the different parts of speech (i.e., noun, verb, adjective, etc.).

\section{Conclusion}

Over the past few decades, much research has been done related to vocabulary learning strategies and learner autonomy. A common point between the two is the need for metacognitive strategies to help the learner think about, evaluate, monitor, troubleshoot, plan, manage, and self-direct the vocabulary learning process. A flowchart such as the one proposed in this paper is a tool that can help foster such metacognitive strategies by helping the learner be more aware of the vocabulary learning process and, therefore, better equipping the learner to become an autonomous learner.

\section{Bio Data}

Aaron Chao is a lecturer at Baiko Gakuin University. His research interests include second language acquisition, learner autonomy, and motivation.

\section{References}

Anderson, N. J. (2003). Teaching reading. In D. Nunan (Ed.), Practical English language teaching (pp. 67-86). New York, NY: McGraw Hill.

Baddeley, A. D. (1997). Human memory: Theory and practice. Hove, England: Psychology Press.

Bauer, L. \& Nation, P. (1993). Word families. International Journal of Lexicography, 6(4), 253-279. https://doi.org/10.1093/ijl/6.4.253

Chamot, A. U. (2009). The CALLA handbook: Implementing the cognitive academic language learning approach (2nd ed.). White Plains, NY: Pearson Education/Longman.

Dunn, R. (1983). Learning style and its relation to exceptionally at both ends of the spectrum. Exceptional Children, 4, 496-506.

$\mathrm{Gu}, \mathrm{Y}$. (2013). Vocabulary learning strategies. In C. A. Chapelle (Ed.), The encyclopedia of applied linguistics. Hoboken, NJ: Blackwell. https://doi.org/10.1002/9781405198431.wbeal1329

Holec, H. (1981). Autonomy and foreign language learning. Oxford, England: Pergamon.
Ma, Q., and Kelly, P. (2006). Computer assisted vocabulary learning: Design and evaluation. Computer Assisted Language Learning, 19(1), 15-45. https://doi.org/10.1080/09588220600803998

Moir, J., \& Nation, I. S. P. (2002). Learners' use of strategies for effective vocabulary learning. Prospect, 17, 15-35.

Nation, I. S. P. (2006). How large a vocabulary is needed for reading and listening? Canadian Modern Language Review, 63, 59-82. https://doi.org/10.3138/cmlr.63.1.59

Nation, I. S. P. (2008). Teaching vocabulary: Strategies and techniques. Boston, MA: Heinle, Cengage Learning.

Nation, I. S. P. (2013). Learning vocabulary in another language. Cambridge, England: Cambridge University Press.

O’Malley, J. M., Chamot, A. U., Stewner-Mazanares, G., Russo, R., \& Kupper, L. (1985). Learning strategies applications with students of English as a second language. TESOL Quarterly, 19, 557 584

Perkins, D. (1992). Smart schools: Better thinking and learning for every child. New York, NY: Free Press.

Schmitt, N. (1997). Vocabulary learning strategies. In D. N. Schmitt \& M. McCarthy (Eds.), Vocabulary: Description, acquisition and pedagogy (pp. 199-227). Cambridge, England: Cambridge University Press.

Schmitt, N. (2008). Review article: Instructed second language vocabulary learning. Language Teaching Research, 12, 329-363. https://doi.org/10.1177/1362168808089921

Singleton, D. (1999). Exploring the second language mental lexicon. Cambridge, England: Cambridge University Press.

Walters, J., \& Bozkurt, N. (2009) The effect of keeping vocabulary notebooks on vocabulary acquisition. Language Teaching Research, 13, 403-423. https://doi. org/10.1177/1362168809341509

Webb, S., \& Nation, P. (2017). How vocabulary is learned. Oxford, England: Oxford University Press. Wilkins, D. (1972). Linguistics in language teaching. London, England: Edward Arnold. 